\title{
Localization by Autoradiography of Synthesis of $(1 \rightarrow 3)-\beta$ and $(1 \rightarrow 6)-\beta$ Linkages in a Wall Glucan during Hyphal Growth of Schizophyllum commune
}

\author{
By J. H. SIETSMA, A. M. S. SONNENBERG† AND \\ J. G. H. WESSELS* \\ Department of Plant Physiology, Biological Centre, University of Groningen, Kerklaan 30, \\ 9751 NN Haren, The Netherlands
}

(Received 15 November 1984; revised 14 January 1985)

\begin{abstract}
Labelling of the hyphal walls of basidiospore germlings of Schizophyllum commune with radioactive glucose resulted in immediate labelling of the glucans but labelling of chitin was delayed for about $20 \mathrm{~min}$. Radioactive glucose could thus be used as a specific label for wall glucans in a $10 \mathrm{~min}$ labelling pulse. Special attention was given to the alkali-insoluble glucans containing ( $1 \rightarrow 3)-\beta$ and $(1 \rightarrow 6)-\beta$ linkages and occurring in close association with chitin. Using [3${ }^{3} \mathrm{H}$ ]glucose and treating the labelled glucans with periodate, a distinction could be made between glucose residues incorporated in $(1 \rightarrow 3)$ and in $(1 \rightarrow 6)$ linkages and the spatial distribution of these synthetic activities could be followed by microautoradiography. The results indicated that in growing hyphae the alkali-insoluble glucan synthesized at the apex was very rich in $(1 \rightarrow 3)$ linkages and that synthesis of $(1 \rightarrow 6)$ linkages increased subapically from about $10 \%$ at the apex to about $60 \%$ just outside the extension zone. Inhibition of hyphal growth with cycloheximide or by low glucose concentrations inhibited glucan synthesis at the apex but not in subapical parts. At the same time a shift towards synthesis of $(1 \rightarrow 6)$ linkages was observed at the apex.
\end{abstract}

\section{INTRODUCTION}

Previous work on wall biogenesis in growing hyphae of Schizophyllum commune (Wessels et al., 1983; Vermeulen \& Wessels, 1984) has suggested that at the growing hyphal tip chitin and $\beta$ glucans are excreted as individual polymers but are then cross-linked in situ at a relatively slow rate. The arising chitin-glucan complex is thought to endow the wall with increasing rigidity, explaining the presumed gradient in rigidity required in the extension zone for the occurrence of hyphal morphogenesis (Green, 1974; Trinci \& Saunders, 1977; Koch, 1982; Wessels, 1984).

The glucan chains in the alkali-insoluble chitin-glucan complex of mature walls contain both $(1 \rightarrow 3)-\beta$ and $(1 \rightarrow 6)-\beta$ linkages (Sietsma \& Wessels, 1977, 1979). On the other hand, a hot-watersoluble glucan at the apex which becomes gradually insolubilized by linkage to chitin appeared

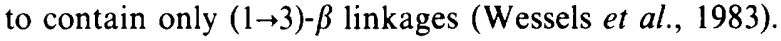

We therefore examined the synthesis of the two types of linkages in the alkali-insoluble glucans along the hyphae by autoradiography. We made use of the fact, described in this paper, that radioactivity from added glucose rapidly appears in polymeric glucose but not in polymeric $\mathrm{N}$-acetylglucosamine. Using a short labelling time $(10 \mathrm{~min})$ we could thus avoid labelling of chitin. For labelling we used glucose with ${ }^{3} \mathrm{H}$ attached to $\mathrm{C}-3$. Autoradiography was then done before and after periodate oxidation, which removes the label at C-3 when the glucose is involved in $(1 \rightarrow 6)$ linkage. The results show that in growing hyphae the alkali-insoluble $\beta$-glucan synthesized at the tip is primarily $(1 \rightarrow 3)$-linked but that $(1 \rightarrow 6)$ linkages appear subapically. This pattern is drastically changed when growth is inhibited by cycloheximide or low glucose in the medium.

† Present address: Mushroom Experiment Station, Peelheideweg 1, America, The Netherlands. 


\section{METHODS}

Growth of hyphae. Basidiospores from a dikaryon of Schizophyllum commune 1-40 (CBS 344.81) $\times 1-50$ (CBS 342.81) were grown on minimal medium in shaken cultures at $24^{\circ} \mathrm{C}$ for $16 \mathrm{~h}$ (Wessels et al., 1983).

Radioactive labelling and isolation of wall fraction. After $16 \mathrm{~h}$ of growth the hyphae were labelled by adding [U$\left.{ }^{14} \mathrm{C}\right]$ glucose $\left(150 \mathrm{mCi} \mathrm{nmol}^{-1} ; \mathrm{i} \mathrm{mCi}=37 \mathrm{MBq}\right), N$-acetyl[ $\left[1-{ }^{-14} \mathrm{C}\right] \mathrm{glucosamine}\left(50 \mathrm{mCi} \mathrm{mmol}^{-1}\right),\left[3-{ }^{3} \mathrm{H}\right] \mathrm{glucose}$ $\left(20 \mathrm{Ci} \mathrm{mmol}^{-1}\right)$, or $\left[2{ }^{3} \mathrm{H}\right]$ glucose $\left(20 \mathrm{Ci} \mathrm{mmol}^{-1}\right)$ (all obtained from New England Nuclear). Growth was stopped by adding 2 vols methanol, the precipitate was collected by centrifugation and washed with $66 \%$ ethanol after which cytoplasmic components were extracted with a $1 \mathrm{M}-\mathrm{KOH} / \mathrm{ethanol} \mathrm{mixture}(1: 2, \mathrm{v} / \mathrm{v})$ at $60^{\circ} \mathrm{C}$ for $20 \mathrm{~min}$ and the residue was washed with $66 \%$ ethanol until neutral.

Labelling of glucose and glucosamine in the wall fraction. After addition of $\left[\mathrm{U}-{ }^{14} \mathrm{C}\right] \mathrm{glucose}\left(7.5 \mu \mathrm{Ci} \mathrm{ml} \mathrm{m}^{-1}\right)$ or $\mathrm{N}$ acetyl[ $\left.1{ }^{-14} \mathrm{C}\right]$ glucosamine $\left(5 \cdot 0 \mu \mathrm{Ci} \mathrm{ml}^{-1}\right)$ to basidiospore germlings, samples were taken at various times up to $60 \mathrm{~min}$. The wall fraction was isolated, treated with $6 \mathrm{M}-\mathrm{HCl}$ at $120^{\circ} \mathrm{C}$ for $30 \mathrm{~min}$ to effect dissolution and partial hydrolysis and the hydrolysate was taken to dryness over $\mathrm{KOH}$ and $\mathrm{P}_{2} \mathrm{O}_{5}$. It was hydrolysed to completion with $0.25 \mathrm{M}-\mathrm{HCl}$ in the presence of $2 \mathrm{~g}$ per $5 \mathrm{ml}$ of Dowex $50 \mathrm{~W}-\mathrm{X} 8(200-400 \mathrm{mesh})$ in the $\mathrm{H}^{+}$form at $100{ }^{\circ} \mathrm{C}$ for $24 \mathrm{~h}$. The Dowex was eluted with $2 \mathrm{M}-\mathrm{HCl}(2$ vols) and the eluate was taken to dryness and dissolved in water. This procedure was effective in hydrolysing both the chitin and the glucan in the wall fraction with minimal destruction of the monomers. The hydrolysate was then applied to a cellulose thin-layer plate and chromatographed with ethyl acetate/pyridine/acetic acid/water $(5: 5: 1: 3$, by vol.). Radioactive glucose and glucosamine were located with a scanner (Berthold) and the cellulose in the relevant areas was scraped from the plates and extracted with water. Radioactivity in the eluates was measured by liquid scintillation and the amount of glucose or glucosamine was determined by a glucose oxidase method (the GOD-PAP test; Boehringer) or the colorimetric method of Johnson (1971), respectively. The specific activities of glucose and glucosamine were then calculated.

Autoradiography of linkage synthesis along the hyphae. Basidiospore germlings were labelled for $10 \mathrm{~min}$ with [3$\left.{ }^{3} \mathrm{H}\right]$ glucose or $\left[2-{ }^{3} \mathrm{H}\right]$ glucose $\left(30 \mu \mathrm{Ci} \mathrm{ml}^{-1}\right)$. Where labelling at different glucose concentrations was compared, the glucose concentration at the time of labelling was first determined (GOD-PAP test; Boehringer) and radioactive glucose was added to obtain identical specific activities $\left(3.5 \mathrm{Ci} \mathrm{mol}^{-1}\right)$. Incorporation was stopped by adding 2 vols methanol and the wall fractions were isolated as above. A part of these was immediately prepared for autoradiography. Another part was used to isolate the chitin-glucan fraction. This was done by extracting watersoluble material with water at $100{ }^{\circ} \mathrm{C}$ for $1 \mathrm{~h}$ and alkali-soluble material [mainly $(1 \rightarrow 3)-\alpha$-glucan] with $1 \mathrm{M}-\mathrm{KOH}$ at $60^{\circ} \mathrm{C}$ for $20 \mathrm{~min}$ (Wessels et al., 1983). To remove traces of contaminating glycogen-like material, the fractions were treated overnight with pancreatic $\alpha$-amylase (EC 3.2.1.1.; Boehringer) $\left(0 \cdot 1 \mathrm{mg} \mathrm{ml}^{-1}\right)$ in 10 mM-phosphate buffer ( $\mathrm{pH} \mathrm{7.5),} 3 \mathrm{~mm}-\mathrm{NaCl}$ under toluene at $30^{\circ} \mathrm{C}$. After washings with water, half of the resulting chitin-glucan fraction was incubated with $50 \mathrm{~mm}$-metaperiodate for $2 \mathrm{~d}$ at $4{ }^{\circ} \mathrm{C}$ in the dark, the other half with water under the same conditions. Samples were then taken and prepared for autoradiography as described by Wessels et al. (1983).

\section{RESULTS}

\section{Delayed labelling of polymeric glucosamine by radioactive glucose}

In previous experiments (Wessels et al., 1983) it was demonstrated that autoradiograms of alkali-extracted walls show grains at the extreme tip of the hyphae after short ( $10 \mathrm{~min})$ labelling with $\mathrm{N}$-acetyl $\left[{ }^{3} \mathrm{H}\right]$ glucosamine but not after labelling with $\left[{ }^{3} \mathrm{H}\right]$ glucose when labelling was greater subapically. This suggests that during the short exposure to radioactive glucose the chitin in the wall was not labelled.

Since chitin is not oxidized by periodate, and we intended to use the removal of radioactivity by periodate as a measure for the percentage of $(1 \rightarrow 6)$ linkages in the glucan, it was essential to prove that chitin was not labelled by a short exposure to radioactive glucose. Basidiospore germlings were labelled for various times with either $\left[\mathrm{U}-{ }^{14} \mathrm{C}\right]$ glucose or $\mathrm{N}$-acetyl[ $\left[1-{ }^{14} \mathrm{C}\right]$ glucosamine and glucose and glucosamine were recovered from the wall fraction as described in Methods. Fig. 1 (a) shows that, after adding radioactive glucose to the medium, glucose monomers in the wall are labelled almost immediately and the specific radioactivity of the glucose rises linearly with time of labelling. However, labelling of the glucosamine in the wall has a lag of about $20 \mathrm{~min}$. Such a lag is not observed when labelling is done with radioactive $\mathrm{N}$ acetylglucosamine (Fig. $1 b$ ): the specific radioactivity in glucosamine rises linearly from the start of labelling while no radioactivity is observed in the glucose isolated from the walls. Apparently the radioactive glucose taken up is considerably diluted by pools of intermediates in the pathway leading from glucose to $N$-acetylglucosamine. 


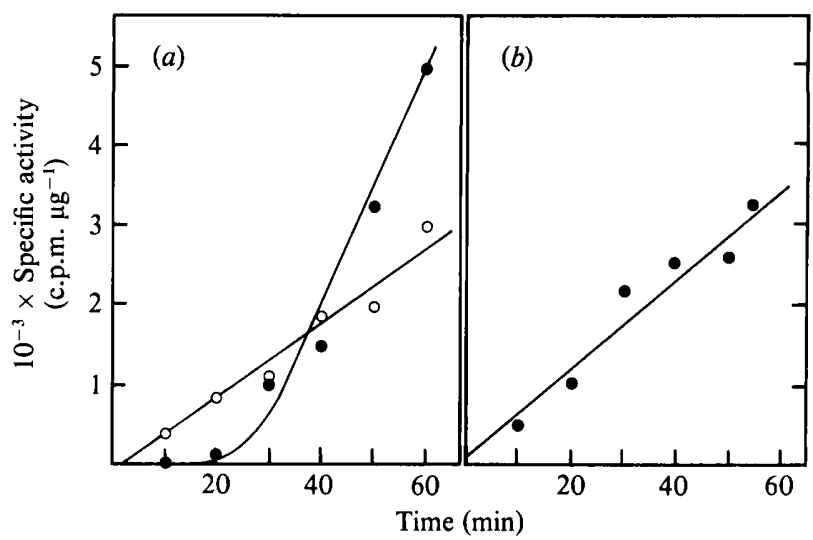

Fig. 1. Time course of incorporation of radioactive glucose and $\mathrm{N}$-acetylglucosamine into glucose and glucosamine isolated from the hyphal wall by hydrolysis. Basidiospore germlings were labelled for various times with $\left[\mathrm{U}^{1{ }^{4}} \mathrm{C}\right] \mathrm{glucose}(a)$ or $\mathrm{N}$-acetyl[ $\left[1-{ }^{14} \mathrm{C}\right] \mathrm{glucosamine}(b)$. The wall fractions were isolated and from these the glucose and glucosamine monomers, as described in Methods. The specific radioactivity of glucosamine $(O)$ and glucose $(O)$ was then determined. Straight lines were calculated from regression analysis (correlation coefficient 0.98 ). The curved line was drawn by hand.

This experiment indicates that a $10 \mathrm{~min}$ pulse of radioactive glucose can be safely used to label the glucan component specifically. In addition to chitin (about $23 \%$ ) the chitin-glucan complex also contains about $9.5 \%$ amino acids (Sietsma \& Wessels, 1979). The time course of labelling of these amino acids by radioactive glucose is unknown but can be expected to be also delayed. If not, their small contribution to the labelling would not be significant.

A curious result from Fig. $1(a)$ is that, after the initial lag, the specific radioactivity in glucosamine rises faster than that in glucose. This could be due to a methodological artefact such as preferential hydrolysis of newly synthesized chitin (Vermeulen \& Wessels, 1984). Alternatively it reflects a temporary intercalary synthesis of septa which are rich in chitin (van der Valk et al., 1977). Autoradiograms of these young hyphae after labelling with $\mathrm{N}$ acetyl $\left[{ }^{3} \mathrm{H}\right]$ glucosamine often show heavy incorporation of label at several septal sites simultaneously (results not shown).

\section{Localization of the synthesis of $(1 \rightarrow 3)$ and $(1 \rightarrow 6)$ linkages in the chitin-glucan complex of growing hyphae}

In glucan synthesized from $\left[3-{ }^{3} \mathrm{H}\right]$ glucose, periodate should remove the label as ${ }^{3} \mathrm{HCOOH}$ if the glucose molecules are $(1 \rightarrow 6)$ linked but not if they are $(1 \rightarrow 3)$ linked. Basidiospore germlings $(16 \mathrm{~h})$ were labelled for $10 \mathrm{~min}$ with either $\left[3-{ }^{3} \mathrm{H}\right]$ glucose or $\left[2-{ }^{3} \mathrm{H}\right]$ glucose as a control. The chitin-glucan complex, retaining the shape of the hyphae, was isolated and treated with $\alpha$ amylase to remove any contaminating glycogen. The radioactivity along the hyphae was then estimated by autoradiography before and after periodate oxidation. In the case of labelling with $\left[3-{ }^{3} \mathrm{H}\right]$ glucose the grains disappearing after periodate oxidation would represent glucose residues that are $(1 \rightarrow 6)$-linked during the labelling period, the grains remaining being those involved in $(1 \rightarrow 3)$ linkage.

Periodate only removed label from the chitin-glucan complex when it was labelled with [3$\left.{ }^{3} \mathrm{H}\right]$ glucose and not when labelling was done with $\left[2-{ }^{3} \mathrm{H}\right] \mathrm{glucose}$. In Fig. $2(e, f)$ the label removed by periodate oxidation is given as a percentage of the label present before oxidation and thus Fig. $2(f)$ can be interpreted as expressing the percentage of $(1 \rightarrow 6)$ linkages synthesized in the chitin-glucan complex along the hyphae. Apparently the glucan which becomes associated with chitin in the apical region contains fewer $(1 \rightarrow 6)$ linkages than in the subapical region.

In the previous experiment the segments measured were $3 \mu \mathrm{m}$ in length, larger than the apical extension zone (about $1.8 \mu \mathrm{m}$ ). Therefore the experiment was repeated measuring sections $0.6 \mu \mathrm{m}$ in length. Fig. $3(b, c, j)$ suggests that the glucan in the chitin-glucan complex made near 


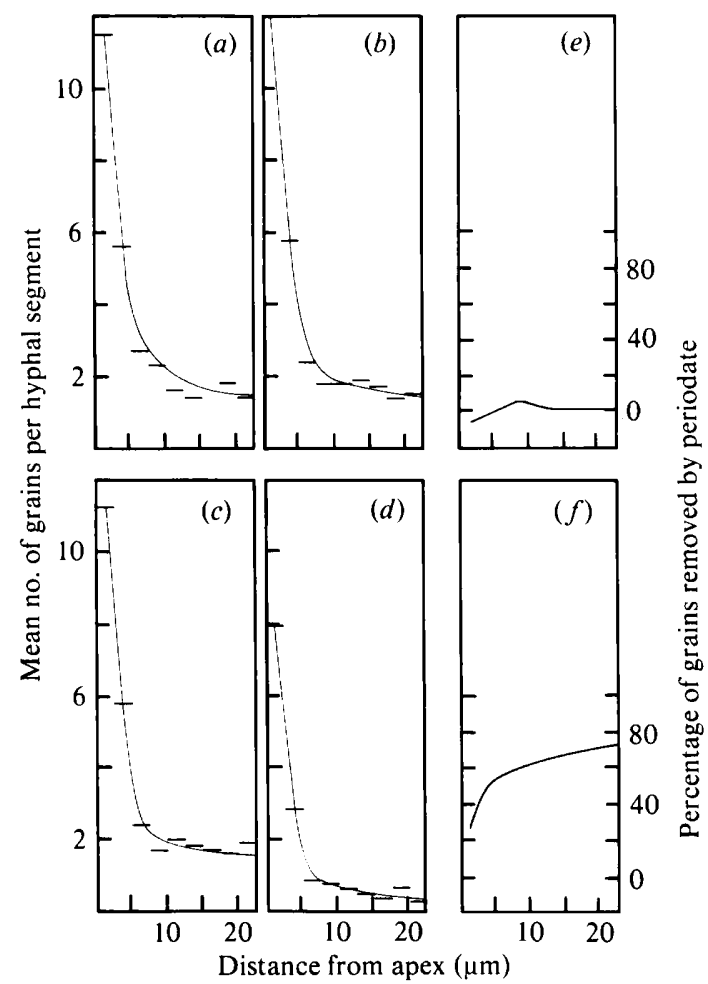

Fig. 2. Autoradiography of the chitin-glucan complex after labelling of basidiospore germlings $(16 \mathrm{~h}$ old) for $10 \mathrm{~min}$ with $\left[2-^{3} \mathrm{H}\right]$ glucose $(a, b, e)$ or $\left[3-{ }^{3} \mathrm{H}\right]$ glucose $(c, d, f)$. Grains were counted in $3 \mu \mathrm{m}$ segments before $(a, c)$ and after $(b, d)$ periodate oxidation. The percentage of grains disappearing was then calculated $(e, f)$. Grain counts represent the mean of counts on 120 hyphae.

the apex is mainly $(1 \rightarrow 3)$ linked but that the percentage of $(1 \rightarrow 6)$ linkages rapidly increases in the extension zone to become almost constant just outside the extension zone. Fig. 3( $a, b, c)$ also shows that the amount of chitin-associated glucan synthesized increases just behind the extreme tip, to reach a maximum value in the extension zone and then drops again. This pattern of synthesis was observed earlier (Wessels et al., 1983) and interpreted as the generation of the alkali-insoluble glucan from a water-soluble $(1 \rightarrow 3)-\beta$-glucan precursor maximally synthesized at the extreme tip.

\section{Localization of the synthesis of $(1 \rightarrow 3)$ - and $(1 \rightarrow 6)$-linked glucan in the chitin-glucan complex of} hyphae inhibited in growth

The growth of hyphae was inhibited by culturing in low-glucose medium or in high-glucose medium in the presence of cycloheximide. Basidiospore germlings ( $16 \mathrm{~h}$ old $)$ were harvested by filtration and resuspended in minimal medium with either $2.5 \mathrm{mg}$ glucose $\mathrm{ml}^{-1}$ (high glucose) or no glucose (low glucose). After $2 \mathrm{~h}$ incubation the cultures were labelled for $10 \mathrm{~min}$ with [3${ }^{3} \mathrm{H}$ ]glucose in such a way that the specific activity of glucose in both cultures was the same $\left(3.5 \mu \mathrm{Ci} \mathrm{mol}^{-1}\right)$ while the high-glucose and low-glucose cultures contained 2.3 and $0.23 \mathrm{mg}$ glucose $\mathrm{ml}^{-1}$, respectively. To part of the high-glucose culture $5 \mu \mathrm{g}$ cycloheximide $\mathrm{ml}^{-1}$ was added before labelling.

Comparing the total amount of wall glucans synthesized (Fig. $3 a, d, g$ ) it is clear that under growth-inhibiting conditions apical synthesis is reduced but subapical synthesis may even be enhanced. Considering the grains caused by the chitin-glucan complex (Fig. $3 b, e, h$ ), the decrease in apical synthesis is again evident but there is still considerable subapical synthesis of the alkali-insoluble glucan in the growth-inhibited hyphae. However, compared to normal 


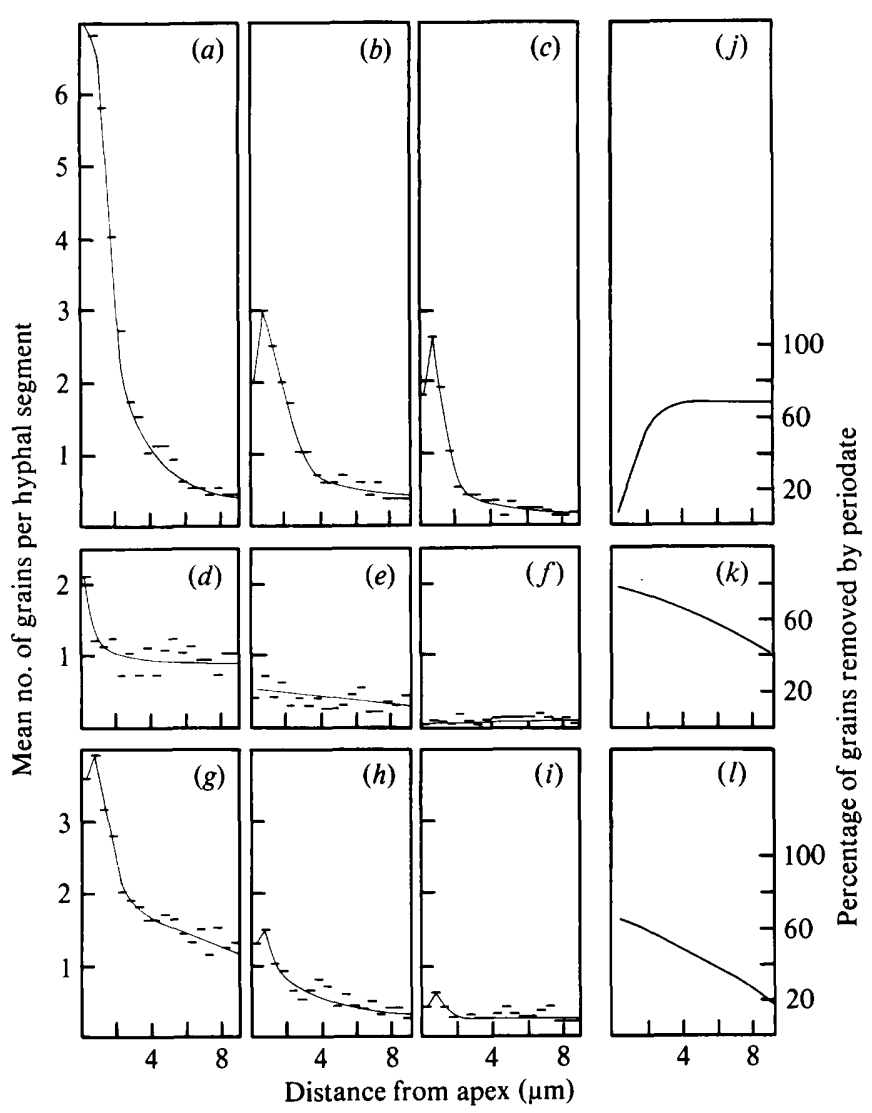

Fig. 3. Autoradiography of total glucan and the chitin-glucan complex after labelling growing and growth-inhibited basidiospore germlings with $\left[3-{ }^{3} \mathrm{H}\right]$ glucose for $10 \mathrm{~min} .(a, b, c, j)$ Hyphae in $2 \cdot 3 \mathrm{mg}$ glucose $\mathrm{ml}^{-1} ;(d, e, f, k)$ hyphae in $0.23 \mathrm{mg}$ glucose $\mathrm{ml}^{-1} ;(g, h, i, l)$ hyphae in $2.3 \mathrm{mg}$ glucose ml $\mathrm{ml}^{-1}$ plus $5 \mu \mathrm{g}$ cycloheximide $\mathrm{ml}^{-1}$. Grains were counted in $0.6 \mu \mathrm{m}$ segments of hyphae immediately after alkali/ethanol extraction (total glucan) $(a, d, g)$ and after extractions revealing the chitin-glucan complex before $(b, e, h)$ and after $(c, f, i)$ periodate oxidation. The percentage of grains disappearing by the periodate oxidation was calculated $(j, k, l)$. Grain counts represent the mean of counts on 120 hyphae.

cultures, a larger part of the label in the alkali-insoluble glucan can be removed in these growthinhibited cultures (Fig. $3 c, f, i$ ), indicating the synthesis of a preponderance of $(1 \rightarrow 6)$ linkages. Calculated over the $10 \mu \mathrm{m}$ segment the periodate removed $32 \%, 70 \%$ and $53 \%$ of the label in hyphae of the high-glucose, low-glucose and cycloheximide-inhibited cultures, respectively. Moreover, in growth-inhibited hyphae the high percentage of synthesis of $(1 \rightarrow 6)$ linkages was particularly evident at the hyphal apex, contrary to the pattern observed in growing hyphae (Fig. $3 j, k, l$ ).

\section{DISCUSSION}

Fungal hyphae grow by apical extension and in microautoradiograms heavy labelling of the wall can be seen at the apex after administration of radioactive $\mathrm{N}$-acetylglucosamine or glucose (Bartnicki-Garcia \& Lippman, 1969; Gooday, 1971 ; Katz \& Rosenberger, 1971 ; Wessels et al., 1983). However, labelled wall polymers are not exclusively synthesized at the hyphal apex as has been tacitly assumed by various authors. For instance, Polacheck \& Rosenberger (1975) have assumed that briefly labelled wall material, which they showed to be very susceptible to autolysins, must be equated with apical wall material. On the other hand, Girard \& Fèvre (1984) 
have suggested that apical and subapical parts of hyphae may differ in the kind of wall polymers that they synthesize.

As shown in the present and in previous autoradiographic studies with $S$. commune (Gooday, 1971; Wessels et al., 1983), a considerable part of the wall glucans is actually synthesized subapically. This material may easily amount to more than $50 \%$ of the total, even in $50 \mu \mathrm{m}$ long germlings, because of the large area involved. It now appears that the alkali-insoluble $\beta$-glucan deposited at the apex in the extension zone is mainly $(1 \rightarrow 3)-\beta$-linked and may be devoid of any $(1 \rightarrow 6)-\beta$ linkages at the extreme apex. The $(1 \rightarrow 6)$ - $\beta$-linked glucosyl residues occur in the extension zone but form the majority in the subapically synthesized glucan. These results do not permit firm conclusions concerning subapical synthesis of one or more glucans with variation in the $(1 \rightarrow 3)-\beta$ and $(1 \rightarrow 6)-\beta$ linkages that they contain. However, previous chemical studies on the accumulated alkali-insoluble $\beta$-glucan of $S$. commune (Sietsma \& Wessels, 1977, 1979) suggest that the mature wall contains very little pure $(1 \rightarrow 3)$ - $\beta$-glucan chains. Thus it seems probable that any alkali-insoluble pure $(1 \rightarrow 3)-\beta$-glucan chains deposited in the wall are subsequently modified by attachment of $(1 \rightarrow 6)-\beta$-linked branches.

The spatial pattern of synthesis of the $(1 \rightarrow 3)-\beta$ and $(1 \rightarrow 6)-\beta$ linkages in the alkali-insoluble glucan may be relevant for the process of hyphal morphogenesis. Previously it was shown that the $\beta$-glucan at the very apex is in a water/alkali-soluble form and is gradually converted into an alkali-insoluble form, presumably by linkage to chitin (Wessels et al., 1983), while at the same time chitin was shown to undergo a transition which decreased its susceptibility to chitinase and dilute acid (Vermeulen \& Wessels, 1984). These changes, occurring in the extension zone, were interpreted as being due to linkages of the glucan chains to chitin chains concomitant with crystallization of chitin and glucan chains to produce a rigid chitin-glucan complex. The fact that the first glucan chains insolubilized at the apex are $(1 \rightarrow 3)-\beta$-linked and contain few, if any $(1 \rightarrow 6)-\beta$ linkages is in line with the observation that the presumed water/alkali-soluble polymeric precursor for this glucan is also mainly $(1 \rightarrow 3)$ - $\beta$-linked (Wessels et al., 1983). This structure of the alkali-insoluble glucan in the extension zone would also facilitate the formation of stable triple helices from the chains (Jelsma \& Kreger, 1975; Marchessault et al., 1977; Marchessault \& Deslandes, 1980). This is required for cross-linking the chitin chains which may be involved in microfibril formation at the same time (Wessels et al., 1983; Wessels, 1984). In the mature wall about half of the $(1 \rightarrow 3)-\beta$-glucan chains attached to chitin contain single glucose branches that are $(1 \rightarrow 6)$ - $\beta$-linked to the main chain while the other half also contains longer branches of $(1 \rightarrow 6)$ $\beta$-linked glucan chains (Sietsma \& Wessels, 1979). At least the presence of single glucose branches does not eliminate the tendency of the $(1 \rightarrow 3)-\beta$-glucans to form triple helices (Sato $e t$ $a l ., 1981)$. However, the role of the $(1 \rightarrow 6)-\beta$ linkages remains unknown.

At low glucose concentration or in the presence of cycloheximide, conditions that impair extension, the apical synthesis of the alkali-insoluble $(1 \rightarrow 3)-\beta$-glucan ceases but subapical synthesis of alkali-insoluble $(1 \rightarrow 3)-\beta-/(1 \rightarrow 6)-\beta$-glucan continues at a slightly lower rate. As shown in Fig. 3 the subapical synthesis of the alkali-soluble glucan $[(1 \rightarrow 3)-\alpha$-glucan] may even be enhanced. Apparently apical synthesis is much more sensitive to these conditions than deposition of glucans in subapical parts. Studying the incorporation of $N$-acetylglucosamine, Katz \& Rosenberger (1971) also showed cessation of apical labelling of Aspergillus nidulans hyphae but increased labelling subapically after cycloheximide addition or osmotic shock. This change in the pattern of $\mathrm{N}$-acetylglucosamine incorporation was interpreted as being due to displacement of chitin synthesis. We have observed a similar phenomenon in $S$. commune after addition of cycloheximide or puromycin (unpublished observation). In the case of incorporation of radioactive glucose into the alkali-insoluble glucan, it is not so much displacement of the synthetic machinery but a decrease in the synthesis of $(1 \rightarrow 3)-\beta$ linkages, particularly at the apex, which is noted after inhibition of growth. In the inhibited systems the synthesis of $(1 \rightarrow 6)-\beta$ linkages is hardly inhibited and even extends over the apices. In regenerating protoplasts of $S$. commune it has been shown that cycloheximide specifically inhibits the synthesis of the watersoluble $(1 \rightarrow 3)$ - $\beta$-glucan precursor, but not its subsequent linkage to chitin, whereas the synthesis of $(1 \rightarrow 3)-\alpha$-glucan and chitin were less affected (Sonnenberg et al., 1982). Possibly this also applies to growing hyphae. 
This study was supported by the Foundation for Fundamental Biological Research (BION), which is subsidized by the Netherlands Organization for the Advancement of Pure Research (ZWO).

\section{REFERENCES}

Bartnicki-Garcia, S. \& Lippman, E. (1969). Fungal morphogenesis: cell wall construction in Mucor rouxii. Science $165,302-304$.

GIRARD, V. \& FÈVRE, M. (1984). Distribution of $(1 \rightarrow 3)$ $\beta$ - and $(1 \rightarrow 4)$ - $\beta$-glucan synthases along the hyphae of Saprolegnia monoica. Journal of General Microbiology 130, 1557-1562.

GooDAY, G. W. (1971). An autoradiographic study of hyphal growth of some fungi. Journal of General Microbiology 67, 125-133.

GREEN, P. B. (1974). Morphogenesis of the cell and organ axis. Biophysical models. Brookhaven Symposia in Biology 25, 166-190.

JeLSMA, J. \& KREGER, D. R. (1975). Ultrastructural observation on $(1 \rightarrow 3)-\beta$-D-glucan from fungal cell walls. Carbohydrate Research 43, 200-203.

JoHnSON, A. R. (1971). An improved method of hexosamine determination. Analytical Biochemistry 44, 628-632.

KATZ, D. \& Rosenberger, R. F. (1971). Hyphal wall synthesis in Aspergillus nidulans: effect of protein synthesis inhibition and osmotic shock on chitin insertion and morphogenesis. Journal of Bacteriology 108, 184-190.

KoCH, A. L. (1982). The shape of the hyphal tips of fungi. Journal of General Microbiology 128, 947-951.

MaRchessault, R. H. \& Deslandes, Y. (1980). Texture and crystal structure of fungal polysaccharides. In Fungal Polysaccharides. A. C. S. Symposium series 126, pp. 221-250. Edited by P. A. Sandford \& K. Matsuda. Washington, DC; American Chemical Society.

Marchessault, R. H., Deslandes, Y., Ogawa, K. \& SUNDARARAJAN, P. R. (1977). X-ray diffraction data for $\beta$ - $(1 \rightarrow 3)$-D-glucan. Canadian Journal of Chemistry 55, 300-303.

Polacheck, Y. \& Rosenberger, R. F. (1975). Autolytic enzymes in hyphae of Aspergillus nidulans: their action on old and newly formed walls. Journal of Bacteriology 121, 332-337.

Sato, T., Norisuye, T. \& Fujita, H. (1981). Melting behaviour of Schizophyllum commune polysaccharides in mixtures of water and dimethyl-sulfoxide. Carbohydrate Research 95, 195-204.

Sietsma, J. H. \& Wessels, J. G. H. (1977). Chemical analysis of the hyphal wall of Schizophyllum commune. Biochimica et biophysica acta 496, 225239.

Sietsma, J. H. \& Wessels, J. G. H. (1979). Evidence for covalent linkages between chitin and $\beta$-glucan in a fungal wall. Journal of General Microbiology 114, 99108.

Sonnenberg, A. S. M., Sietsma, J. H. \& Wessels, J. G. H. (1982). Biosynthesis of alkali-insoluble cellwall glucan in Schizophyllum commune protoplasts. Journal of General Microbiology 128, 2667-2674.

Trincl, A. P. J. \& SAunders, P. T. (1977). Tip growth of fungal hyphae. Journal of General Microbiology 103, 243-248.

VALK, P. VAN DER, MARChant, R. \& Wessels, J. G. H. (1977). Ultrastructural localization of polysaccharides in the wall and septum of the basidiomycete Schizophyllum commune. Experimental Mycology 1, 69-82.

Vermeulen, C. A. \& Wessels, J. G. H. (1984). Ultrastructural differences between wall apices of growing and non-growing hyphae of Schizophyllum commune. Protoplasma 120, 123-131.

Wessels, J. G. H. (1984). Apical hyphal wall extension. Do lytic enzymes play a role? In Microbial Cell Wall Synthesis and Autolysis, pp. 31-42. Edited by C. Nombela. Amsterdam: Elsevier Science Publishers. Wessels, J. G. H., Sietsma, J. H. \& Sonnenberg, A. S. M. (1983). Wall synthesis and assembly during hyphal morphogenesis in Schizophyllum commune. Journal of General Microbiology 129, 1607-1616. 